\title{
Quantitative Structure-Toxicity Relationship for Predicting Acute Toxicity of Phenols
}

\author{
Zhi-Xiang ZHOU ${ }^{1, a, ~ *, ~ M e n g-N a n ~ Q I N ~}{ }^{1}$, Yang-Hua LIU ${ }^{1}$, \\ Xiao-Long ZHANG ${ }^{1}$, Han-Dong $\mathrm{LI}^{2}$ \\ ${ }^{1}$ College of Life science and Bioengineering, Beijing University of Technology China \\ ${ }^{2}$ Chinese Research Academy of Environmental Sciences, China \\ aemail: zhouzhixiang@bjut.edu.cn \\ ${ }^{*}$ Corresponding author
}

Keywords: Phenols, QSTR, Acute toxicity.

\begin{abstract}
Phenols represent one of the most important classes of environmental chemicals. Most of them may cause serious public health and environmental problems. The present work is to develop an effective QSTR model for acute toxicity, a toxicological endpoint of Phenols. We calculated various descriptors and used linear regression way to select relevant parameters, and built a QSTR model. The model showed a good forecasting ability. Based on the descriptors, a further discussion was presented for the toxic mechanism.
\end{abstract}

\section{Introduction}

Phenols are important materials or intermediates of explosives, pesticides, organic synthesis, and dyestuffs etc. With the development of industry, thousands of these compounds have being introduced into the environment every year. Most of these chemicals exhibit toxicity, which may cause serious public health problems [1]. With the development of computer technology and quantum chemistry, methods based on quantitative structure-toxicity relationship (QSTR) have been an increasing role in environmental hazard assessment [2]. With this method, we can use parameters named descriptors in QSTR software package. Descriptors can be classified into different types such as topochemical, geometric, constitution, and electron descriptors etc [3]. The values of these descriptors can reflect the structure information of chemicals and help us to have a better insight into the action of mechanism [4]. If the experimental data and the value of descriptors are linearly related to toxicity for a set of molecules, it means the model is successfully established. Once the descriptors selected in QSTR model are related to acute toxicity of the chemical, we can analysis which descriptors influenced the toxicity. If the toxicity of a chemical is unknown, we can calculate its parameters and give it a predicted value for the hazard assessment.

$\mathrm{LD}_{50}(50 \%$ lethal dose concentration) is the toxicological endpoint which has great effect on human health. Therefore, the goal of this study is to use the multiple linear regressions (MLR) technique to develop QSTR models to predict the $\mathrm{LD}_{50}$ of Phenols, based on the most comprehensive data collection available from databases and literature. 


\section{Material and Data}

\section{Descriptors Calculation}

The 2D structures of the compounds obtained from the EPI (Estimation Programs Interface) Suite ${ }^{\mathrm{TM}}$ were optimized based on the AM1 semi empirical method. The descriptors of phenols were calculated by Projectleader of Scigress 7.7 and Dragon software to obtain their $\mathrm{LD}_{50}$.

\section{Model Building}

After the calculation of the molecular descriptors, multiple linear regression (MLR) was carried out to select the most relevant descriptors from the pool of calculated descriptors, and the SPSS program package was used to analyze data and select descriptors, and establish the linear relationship between structure and toxicity in the MLR way at the confidence level of 95\%. When the regression was completed, SPSS showed a form filling with the regression coefficient $\left(\mathrm{R}^{2}\right)$, standard error $(\mathrm{s})$, and Fisher statistic value (F). The best model can be selected with consideration of these values.

\section{Model Validation}

External validation has been considered more reliable for judging the prediction potential of QSAR models than internal validation techniques. For extreme cases, appropriate external datasets are not available for prediction purposes. The (external) predictive capacity of a given model was judged by its application for prediction of the test set toxicity values, and the model's stability was established by a cross-validated regression coefficient $\left(\mathrm{Q}^{2}\right)$. The closer to 1 of the $\mathrm{Q}^{2}$ value, the more stable the model was.

Dataset the experimental values of mouse $\mathrm{LD}_{50}$ were collected from the ChemIDplus database (http://chem.sis.nlm.nih.gov/chemidplus/chemidheavy.jsp), and are shown in Table 1.

Table 1 Experimental $\operatorname{LogLD} \mathrm{D}_{50}$ value and predictive $\operatorname{LogLD}_{50}$ value of phenols

\begin{tabular}{ccccc}
\hline No. & CAS. No. & $\begin{array}{c}\text { Experi- } \\
\text { mental }\end{array}$ & $\begin{array}{c}\text { Predic } \\
\text {-tive }\end{array}$ \\
\hline 1 & $100-02-7$ & 2.45 & 2.79 & -0.34 \\
2 & $106-41-2$ & 2.72 & 2.89 & -0.17 \\
3 & $106-44-5$ & 2.54 & 2.72 & -0.18 \\
4 & $106-48-9$ & 2.56 & 2.84 & -0.28 \\
5 & $108-39-4$ & 2.92 & 2.66 & 0.26 \\
6 & $108-43-0$ & 2.72 & 2.86 & -0.14 \\
7 & $108-73-6$ & 3.66 & 3.29 & 0.37 \\
8 & $108-95-2$ & 2.43 & 1.95 & 0.48 \\
9 & $119-34-6$ & 3.17 & 2.95 & 0.22 \\
10 & $119-36-8$ & 3.05 & 3.43 & -0.38 \\
11 & $120-80-9$ & 2.41 & 2.12 & 0.29 \\
12 & $120-83-2$ & 3.11 & 3.10 & 0.01 \\
13 & $121-33-5$ & 3.59 & 3.62 & -0.03 \\
14 & $123-31-9$ & 2.39 & 2.35 & 0.04 \\
\hline
\end{tabular}

\begin{tabular}{llccc}
\hline No. & CAS. No. & $\begin{array}{c}\text { Experi- } \\
\text { mental }\end{array}$ & $\begin{array}{c}\text { Predic- } \\
\text { tive }\end{array}$ & Reside \\
\hline 15 & $14008-60-7$ & 2.88 & 2.94 & -0.06 \\
16 & $150-19-6$ & 2.49 & 2.97 & -0.48 \\
17 & $1570-64-5$ & 3.12 & 2.98 & 0.14 \\
18 & $17788-00-0$ & 2.9 & 2.86 & 0.04 \\
19 & $2144-08-3$ & 3.34 & 3.04 & 0.30 \\
20 & $2295-58-1$ & 3.44 & 3.20 & 0.24 \\
21 & $487-70-7$ & 3.51 & 3.49 & 0.02 \\
22 & $490-79-9$ & 2.6 & 2.78 & -0.18 \\
23 & $4901-51-3$ & 3.65 & 3.39 & 0.26 \\
24 & $498-02-2$ & 3.95 & 3.52 & 0.43 \\
25 & $50-85-1$ & 3.26 & 3.36 & -0.10 \\
26 & $51-28-5$ & 1.65 & 1.65 & 0.00 \\
27 & $527-60-6$ & 4 & 3.30 & 0.70 \\
28 & $534-52-1$ & 1.32 & 1.41 & -0.09 \\
\hline
\end{tabular}




\begin{tabular}{|c|c|c|c|c|}
\hline No. & CAS. No. & $\begin{array}{l}\text { Experi- } \\
\text { mental }\end{array}$ & $\begin{array}{l}\text { Predic } \\
\text {-tive }\end{array}$ & Reside \\
\hline 29 & $552-41-0$ & 2.69 & 3.05 & -0.36 \\
\hline 30 & $554-84-7$ & 3.03 & 2.86 & 0.17 \\
\hline 31 & $567-61-3$ & 2.4 & 2.64 & -0.24 \\
\hline 32 & $576-26-1$ & 2.65 & 2.77 & -0.12 \\
\hline 33 & $583-78-8$ & 2.98 & 2.56 & 0.42 \\
\hline 34 & $59-50-7$ & 2.78 & 3.13 & -0.35 \\
\hline 35 & $591-27-5$ & 2.6 & 2.81 & -0.21 \\
\hline 36 & $591-35-5$ & 3.38 & 3.29 & 0.09 \\
\hline 37 & $609-99-4$ & 2.43 & 2.60 & -0.17 \\
\hline 38 & $618-45-1$ & 3.21 & 2.72 & 0.49 \\
\hline 39 & $626-02-8$ & 3.46 & 3.32 & 0.14 \\
\hline 40 & $65-45-2$ & 2.48 & 2.86 & -0.38 \\
\hline 41 & $65-49-6$ & 3.6 & 3.56 & 0.04 \\
\hline 42 & $654-42-2$ & 2.27 & 2.50 & -0.23 \\
\hline 43 & $69-72-7$ & 2.68 & 3.07 & -0.39 \\
\hline 44 & $7693-52-9$ & 3.4 & 3.25 & 0.15 \\
\hline 45 & $831-61-8$ & 3.76 & 3.62 & 0.14 \\
\hline 46 & $87-64-9$ & 2.85 & 2.78 & 0.07 \\
\hline 47 & $87-65-0$ & 3.33 & 3.21 & 0.12 \\
\hline 48 & 87-66-1 & 2.48 & 2.76 & -0.28 \\
\hline 49 & $87-86-5$ & 1.56 & 1.85 & -0.29 \\
\hline 50 & 88-04-0 & 3 & 3.17 & -0.17 \\
\hline 51 & $88-75-5$ & 3.11 & 2.73 & 0.38 \\
\hline 52 & $89-56-5$ & 3 & 3.15 & -0.15 \\
\hline 53 & $89-57-6$ & 3.53 & 3.33 & 0.20 \\
\hline 54 & $89-83-8$ & 2.81 & 2.91 & -0.10 \\
\hline 55 & $90-00-6$ & 2.78 & 2.45 & 0.33 \\
\hline 56 & $90-05-1$ & 2.79 & 2.70 & 0.09 \\
\hline 57 & $91-10-1$ & 3.4 & 3.61 & -0.21 \\
\hline 58 & $935-95-5$ & 2.04 & 2.28 & -0.24 \\
\hline 59 & $95-01-2$ & 3.14 & 2.89 & 0.25 \\
\hline
\end{tabular}

\begin{tabular}{|c|c|c|c|c|}
\hline No. & CAS. No. & $\begin{array}{l}\text { Experi- } \\
\text { mental }\end{array}$ & $\begin{array}{c}\text { Predic- } \\
\text { tive }\end{array}$ & Reside \\
\hline 60 & $95-55-6$ & 2.9 & 2.60 & 0.30 \\
\hline 61 & $95-56-7$ & 2.81 & 2.69 & 0.12 \\
\hline 62 & $95-57-8$ & 2.54 & 2.72 & -0.18 \\
\hline 63 & $95-65-8$ & 2.6 & 2.82 & -0.22 \\
\hline 64 & $95-77-2$ & 3.23 & 3.24 & -0.01 \\
\hline 65 & $95-85-2$ & 3.01 & 3.12 & -0.11 \\
\hline 66 & $95-95-4$ & 2.78 & 2.68 & 0.10 \\
\hline 67 & $97-51-8$ & 2.83 & 2.74 & 0.09 \\
\hline 68 & 99-06-9 & 3.3 & 3.10 & 0.20 \\
\hline 69 & 99-24-1 & 3.23 & 3.25 & -0.02 \\
\hline 70 & $99-57-0$ & 2.93 & 3.12 & -0.19 \\
\hline 71 & $99-76-3$ & 3.9 & 3.82 & 0.08 \\
\hline 72 & $99-89-8$ & 2.94 & 3.30 & -0.36 \\
\hline 73 & $99-93-4$ & 3.18 & 3.42 & -0.24 \\
\hline 74 & 99-96-7 & 3.34 & 3.43 & -0.09 \\
\hline 75 & $105-67-9 *$ & 2.91 & 2.83 & 0.08 \\
\hline 76 & $108-46-3^{*}$ & 2.3 & 2.64 & -0.34 \\
\hline 77 & $108-68-9 *$ & 2.68 & 3.01 & -0.33 \\
\hline 78 & $118-95-6 *$ & 1.65 & 2.75 & -1.10 \\
\hline 79 & $1198-55-6 *$ & 2.5 & 0.60 & 1.90 \\
\hline 80 & $504-15-4^{*}$ & 2.89 & 2.91 & -0.02 \\
\hline 81 & $576-24-9 *$ & 3.38 & 3.16 & 0.22 \\
\hline 82 & $58-90-2 *$ & 2.12 & 2.86 & -0.74 \\
\hline 83 & $615-58-7^{*}$ & 2.45 & 3.10 & -0.65 \\
\hline 84 & $618-83-7^{*}$ & 3.84 & 3.04 & 0.80 \\
\hline 85 & $619-19-2^{*}$ & 2.81 & 3.26 & -0.45 \\
\hline 86 & 767-00-0* & 2.65 & 2.44 & 0.21 \\
\hline 87 & $83-40-9 *$ & 3 & 3.06 & -0.06 \\
\hline 88 & $95-48-7 *$ & 2.54 & 2.43 & 0.11 \\
\hline 89 & $95-71-6^{*}$ & 2.6 & 2.40 & 0.20 \\
\hline 90 & $95-87-4^{*}$ & 2.58 & 2.46 & 0.12 \\
\hline
\end{tabular}

\section{Results and Discussion}

Establishment of QSTR. Different descriptors were calculated for the model development with SPSS package. The inter correlation of descriptors were taken into consideration and used for dependent variables. The $\log \mathrm{LD}_{50}$ value was served as independent value from Table1.This model was established by MLR method and shown as follows: 


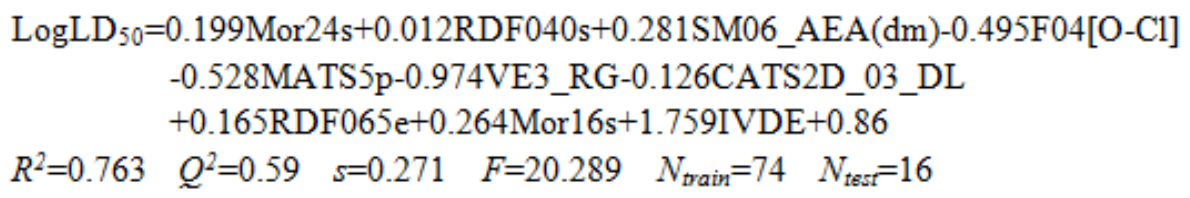

Where $\mathrm{R}^{2}$ is the square of correlation coefficient, $\mathrm{Q}^{2}$ is a cross-validated regression coefficient, $\mathrm{s}$ is the standard error, $\mathrm{F}$ is the mean square radio, and $\mathrm{N}$ is the number of compounds.

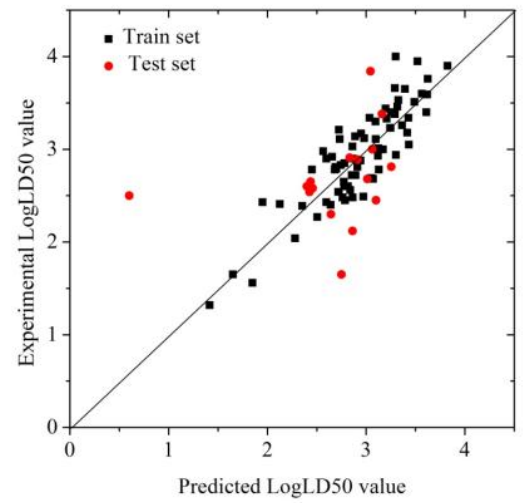

Figure 1. Linear analysis for $\mathrm{LD}_{50} \mathrm{QSTR}$ model of Phenols

The MLR prediction figure (Fig. 1) showed the linear relationship between the predicted and experimental values were good. The predicted value of $\mathrm{LD}_{50}$ and residue can be calculated by this model, the result shows that the residues of the training and test sets are low (Table 1). The correlation coefficient of $\mathrm{R}^{2}$ is 0.763 and the cross-validated regression coefficient of $\mathrm{Q}^{2}$ is 0.59 . This signifies that the model has a strong predicting ability and high stability.

Table 2. Definition of descriptors in $\mathrm{LD}_{50}$ model of Phenols

\begin{tabular}{ll}
\hline \multicolumn{1}{c}{ Descriptors } & \multicolumn{1}{c}{ Definition } \\
\hline Mor24s & signal 24 / weighted by I-state \\
RDF040s & Radial Distribution Function - 040 / weighted by I-state \\
SM06_AEA $(d m)$ & spectral moment of order 6 from augmented edge adjacency mat. weighted \\
& by dipole moment \\
F04[O-Cl\} & Frequency of O - Cl at topological distance 4 \\
MATS5p & Moran autocorrelation of lag 5 weighted by polarizability \\
$V E 3 \_R G$ & logarithmic coefficient sum of the last eigenvector from reciprocal squared \\
& geometrical matrix \\
CATS2D_03_DL & RATS2D Donor-Lipophilic at lag 03 \\
RDF065e & Radial Distribution Function - 065 / weighted by Sanderson \\
& electronegativity \\
Mor16s & signal 16 / weighted by I-state \\
33s & 3rd component size directional WHIM index / weighted by I-state \\
\hline
\end{tabular}

The definitions of the 10 descriptors are shown in Table 2. From Eq. (1), we can see that the $F 04[O-C l], M A T S 5 p, V E 3 \_R G$ and CATS2D_03_DLC-025 were positively correlated with the acute toxicity. As these descriptor parameter values increase, the LogLD50 value decreases, and the acute toxicity of chemicals increases. The other 
descriptors are negatively correlated with the acute toxicity, wherein, Mor $24 s$ was signal 24 / weighted by I-state, Morl6s associated signal 16 / weighted by I-state. This signifies that the reducing polarizability of the molecules tend to decrease the toxicity of the chemical.

\section{Summary}

With MLR analysis, QSTR model for LD50 of phenols was successfully built with the descriptors from AM1 and E-dragon software. The QSTR model showed high stability and excellent predicting properties.

\section{Acknowledgements}

This study was supported by the Ministry of environmental protection of China (Grant No. 2011467037).

\section{References}

[1] Oberg, T.G. Prediction of vapor pressures for halogenated diphenylether congeners from molecular descriptors. Environ. Sci. Pollut. Res. 2002, 9, 405-411.

[2] Leong MK, Lin SW, Chen HB, Tsai FY. Predicting acute toxicity of aromatic amines by various machine learning approaches. Toxicol Sci.Vol. 116 (2010),p:498-513.

[3] Simon-Hettich, B.; Rothfuss, A.; Steger-Hartmann, T. Use of computer-assisted prediction of toxic effects of chemical substances. Toxicology 2006, 224(1-2), 156-162.

[4] Patlewicz, G.; Rodford, R.; Walker, J.D. Quantitative structure-activity relationships for predicting carcinogenicity and carcinogenicity. Environ. Toxicol. Chem. 2003, 22(8), 1885-1893 